Удк 546.41:546.47:546.56:547.572.3

\title{
ОЦЕНКА АНТИОКСИДАНТНОЙ АКТИВНОСТИ КОМПЛЕКСНЫХ СОЕДИНЕНИЙ ДИГИДРОКВЕРЦЕТИНА С ИОНАМИ БИОГЕННЫХ МЕТАЛЛОВ
}

\author{
(C) Е.В. Столповская", Н.Н. Трофимова, В.А. Бабкин
}

\author{
Иркутский институт химии им. А.Е. Фаворского СО РАН, ул. Фаворского, 1, \\ Иркутск, 664033 (Россия), e-mail: stel@irioch.irk.ru
}

\begin{abstract}
Исследована антиоксидантная активность комплексных соединений (КС) цинка, меди (II) и кальция с дигидрокверцетином (ДКВ) в экспериментах in vitro на сливной плазме крови здоровых доноров. Оценка состояния перекисного окисления липидов (ПОЛ) в плазме крови проводилась по содержанию малонового диальдегида (МДА), диеновых (ДК) и триеновых (ТК) конъюгатов. Определено влияние КС и ДКВ на активность фермента каталазы в плазме крови. Установлено, что КС дигидрокверцетина с ионом цинка снижает содержание МДА в плазме крови на 14,9\% по сравнению с контролем, что превосходит в 2 раза этот показатель для ДКВ $(7,5 \%)$. Соответствующие показатели для КС ДКВ с ионами меди (II) и кальция составляют 11,2 и 3,7\%. Влияние комплексов на снижение по сравнению с контролем содержания в плазме крови ДК и ТК сопоставимо с соответствующими показателями для ДКВ. Комплекс ДКВ с ионом цинка увеличивает активность каталазы на 1,5\% по сравнению с ДКВ. Комплексы, содержащие ионы меди (II) и кальция, увеличивают активность каталазы не более чем ДКВ.

Ключевые слова: дигидрокверцетин, комплексные соединения, антиоксидантная активность, малоновый диальдегид, диеновые и триеновые конъюгаты, каталаза.

Работа выполнена при финансовой поддержке Программы Президиума РАН №30 «Фундаментальные исследования для разработки биомедииинских технологий», проект №30.01 «Разработка инновационных лекарственных препаратов антикоагулянтного, противовоспалительного, венопротекторного и ранозаживляющего действия». Основные результаты исследования получены с использованием оборудования Байкальского аналитического иентра коллективного пользования СО РАН.
\end{abstract}

\section{Введение}

Одним из основных механизмов антиоксидантного действия флавоноидов в биологических системах являются реакции с биорадикалами, обусловленные структурными особенностями молекул полифенолов и их функционализацией заместителями - гидроксильными, метильными, гликозидными и другими группами. Так, например, увеличение числа гидроксильных групп в флавоновом остове, наличие карбонильной группы в кольце С повышает склонность такой молекулы к окислению. Наиболее эффективными восстановителями супероксид анион-радикала являются флавоноиды, содержащие орто-гидроксигруппы в кольце В, проявляющие наибольшую склонность к окислению [1].

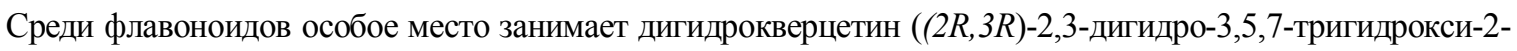
(3,4-дигидроксифенил)-4H-1-бензопиран-4-он) (1, рис. 1) - основной компонент флавоноидной фракции (до

Столповская Елена Владимировна - кандидат химических наук, младший научный сотрудник лаборатории химии древесины, e-mail: stel@irioch.irk.ru Трофимова Наталья Николаевна - кандидат химических наук, старший научный сотрудник лаборатории химии древесины, e-mail: natrof@irioch.irk.ru Бабкин Василий Анатольевич - доктор химических наук, профессор, заведующий лабораторией химии древесины, e-mail: babkin@irioch.irk.ru $85 \%$ ) древесины лиственницы сибирской (Larix sibirica Ledeb.) и лиственницы Гмелина (L. gmelinii (Rupr.) Rupr.). Сочетание разнообразного спектра биологического действия с высоким его содержанием в составе доступного возобновляемого сырья позволило разработать промышленную технологию получения ДКВ [2] и ряда лекарственных препаратов и биологически активных добавок на его основе [3].

\footnotetext{
* Автор, с которым следует вести переписку.
} 
Введение в структуры флавоноидов ионов биогенных металлов в ряде случаев приводит к усилению антиоксидантной активности. Комплексные соединения на основе кверцетина, рутина и галангина, содержащие ионы алюминия и цинка, как установлено, являются более сильными антиоксидантами (АО) по сравнению со свободными флавоноидами $[4,5]$. Комплексообразование физетина с ионом $\mathrm{Fe}^{3+}[6]$, нарингина с ионом $\mathrm{Cu}^{2+}$ [7] также усиливает антиоксидантные свойства исходных флавоноидов. Мориновые комплексы, содержащие ионы $\mathrm{Ca}^{2+}, \mathrm{Mg}^{2+}[8], \mathrm{Cu}^{2+}[9-11], \mathrm{Gd}^{3+}, \mathrm{La}^{3+}, \mathrm{Pt}^{2+}[10,11], \mathrm{MoO}_{4}^{2-}, \mathrm{Zr}^{2+}[12]$, $\mathrm{Sn}^{2+}[13]$, проявляют более высокую антиоксидантную активность по сравнению с морином. Таким образом, многие КС биогенных металлов с флавоноидами являются значительно более эффективными ловушками анион-радикала кислорода по сравнению с исходными полифенолами и обладают усиленной антиоксидантной активностью, иногда в отсутствие проявления подобной активности ионами соответствующих металлов [14].

Целью настоящей работы явилась оценка антиоксидантной активности комплексных соединений цинка (2), меди (II) (3) и кальция (4) на основе дигидрокверцетина, структуры которых были установлены ранее [15] (рис. 1).

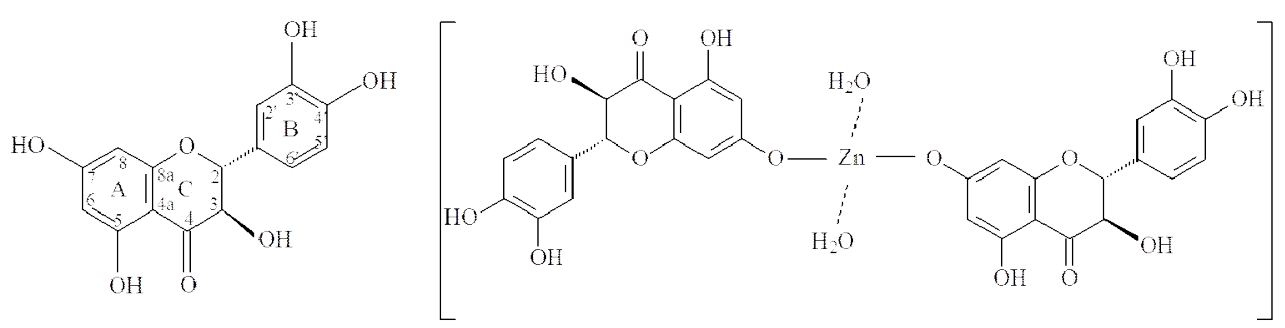

1

2<smiles>O=C1c2c(O)cc(OCCOCCOc3cc(Br)cc(O)c3O)cc2OC(c2ccc(O)c(O)c2)C1O</smiles>

Рис. 1. Структуры дигидрокверцетина и металлосодержащих комплексов на его основе

Исследование антиоксидантного действия как природных, так и синтетических соединений проводят с использованием различных физико-химических методов, биохимических тест-систем и экспериментальных моделей различных уровней [14].

Сопоставительный анализ антиоксидантной активности ДКВ и КС на его основе проводили в экспериментах in vitro на сливной плазме крови здоровых доноров. Влияние КС и ДКВ на процессы перекисного окисления липидов в плазме крови определяли по содержанию малонового диальдегида, возникающего в организме при деградации гидроперекисей липидов активными формами кислорода и служащего маркером ПОЛ и оксидативного стресса, а также диеновых и триеновых конъюгатов, которые представляют собой гидроперекиси липидов с сопряженными двойными связями. Оценивали влияние КС и ДКВ на активность фермента каталазы в плазме крови.

\section{Экспериментальная часть}

Содержание МДА в плазме крови определяли модифицированным методом в тесте ТБК. Расчет содержания МДА, нмоль/л, проводили с учетом разбавления для плазмы К=21,36 [16]. Определение ДК и ТК проводили методом экстракции липидов смесью гептана и изопропилового спирта в объемном соотношении $1: 1$. Содержание ДК рассчитывали на основании значений оптической плотности гептанового экстракта при $\lambda=232$ нм, ТК - при $\lambda=275$ нм. УФ спектры регистрировали на спектрофотометре СФ-26 в кюветах $l=1,0$ см. Количество ДК и ТК в условных единицах (у.е.) рассчитывали по формуле $\mathrm{X}=(\mathrm{D} \cdot 4,5) / 0,3$, где 
$\mathrm{X}$ - содержание ДК или ТК, D - оптическая плотность гептанового слоя для анализируемого раствора [17]. Определение активности каталазы в плазме крови под влиянием анализируемых растворов комплексов и ДКВ проводили спектрофотометрическим методом по цветной реакции с молибдатом аммония [18]. Активность каталазы в анализируемой пробе оценивалась по интенсивности окраски соединения, образующегося в результате реакции пероксида водорода с молибденом, поскольку зависит от количества перекиси, не разрушенной каталазой. Интенсивность окраски измеряли при $\lambda=410$ нм против контрольной пробы, в которую вместо перекиси водорода вносили 2 мл воды. Активность каталазы (\%) рассчитывали по формуле Кат $=100 \cdot\left(\mathrm{D}_{\mathrm{x}}-\mathrm{D}_{\text {оп }}\right) / \mathrm{D}_{\mathrm{x}}$, где $\mathrm{D}_{\mathrm{x}}-$ оптическая плотность холостой пробы, $\mathrm{D}_{\text {оп }}-$ оптическая плотность анализируемой пробы. Каждый из анализируемых растворов исследовали в шести параллельных опытах.

Для определения действующей концентрации КС готовились $1 \%$ суспензии исследуемых веществ в диметилсульфоксиде (ДМСО), из которых были приготовлены растворы в диапазоне концентраций $0,001-0,1 \%$ [19]. Для приготовления анализируемых растворов к 0,5 мл каждого из полученных растворов добавляли по 2,5 мл плазмы крови. В качестве контрольного образца использовали раствор, содержащий плазму крови в ДМСО. Контроль и каждый из анализируемых растворов исследовали в трех параллельных опытах.

Определение растворимости комплексов проводили согласно методике [20]. Все КС нерастворимы в воде, метаноле, этаноле, ацетоне. По растворимости в ДМСО КС цинка и кальция с ДКВ можно отнести к классу малорастворимых соединений: для растворения 1 г вещества необходимо от 100 до 1000 мл растворителя. КС меди (II) с ДКВ относится к классу очень малорастворимых соединений: 1 г вещества растворяется в объеме ДМСО от 1000 до 10000 мл.

Все экспериментальные данные исследования антиоксидантной активности в опытах in vitro были статистически обработаны (P = 95\%) при помощи критерия Стьюдента с вычислением граничных значений доверительного интервала среднего результата и определением ошибки средней арифметической из шести параллельных опытов по стандартным методикам с использованием для расчетов компьютерной программы MS Excel.

\section{Обсуждение результатов}

Определение действующей концентрации растворов КС в ДМСО проводили на основании изменения содержания МДА в плазме крови в присутствии КС и ДКВ по отношению к контрольному опыту. Данные представлены в таблице.

Максимальное снижение содержания МДА в плазме крови по сравнению с контролем наблюдалось при использовании $0,005 \%$ раствора КС цинка с ДКВ. КС меди (II) с ДКВ снижает содержание МДА только в концентрации $0,005 \%$, в растворах остальных представленных концентраций снижения содержания МДА не происходило. Наибольшую активность КС кальция с ДКВ проявляет при концентрации $0,001 \%$. Для сравнительной характеристики антиоксидантной активности полученных комплексов дальнейшие исследования проводились для растворов КС в одинаковой концентрации $0,005 \%$.

Результаты оценки влияния ДКВ и КС на его основе на показатели ПОЛ в плазме крови представлены на рисунках 2, 3 .

Сопоставительный анализ данных, представленных на рисунке 2, демонстрирует, что цинковый комплекс дигидрокверцетина снижает содержание МДА в плазме крови на $14,9 \%$ по сравнению с контролем, что превосходит в 2 раза этот показатель для ДКВ (7,5\%). Комплексы меди (II) и кальция с ДКВ снижают содержание МДА в плазме крови соответственно на 11,2 и 3,7\% по сравнению с контрольным опытом, в котором концентрация МДА в плазме крови к концу реакции (1 ч) составляла 1,61 нмоль/л.

Представленные на рисунке 3 данные показывают, что снижение содержания ДК и ТК по сравнению с контролем под влиянием комплексов сопоставимо с соответствующими показателями для ДКВ.

Снижение содержания МДА в плазме крови по отношению к контрольному опыту в растворах ДКВ (1) и комплексных соединений цинка (2), меди (II) (3) и кальция (4) в ДМСО

\begin{tabular}{c|c|c|c|c}
\hline $\begin{array}{c}\text { Содержание АО в анализи- } \\
\text { руемом растворе, \% }\end{array}$ & \multicolumn{4}{|c}{ Снижение содержания МДА, \% } \\
\cline { 2 - 5 } & $\mathbf{1}$ & $\mathbf{2}$ & $\mathbf{3}$ & $\mathbf{4}$ \\
\hline 0,001 & 11 & 27 & - & 5,6 \\
0,005 & 10 & 27,9 & - & 4,1 \\
0,1 & 5,1 & 13,5 & - & 4,1 \\
1 & 3,3 & 10,2 & - & - \\
\hline
\end{tabular}



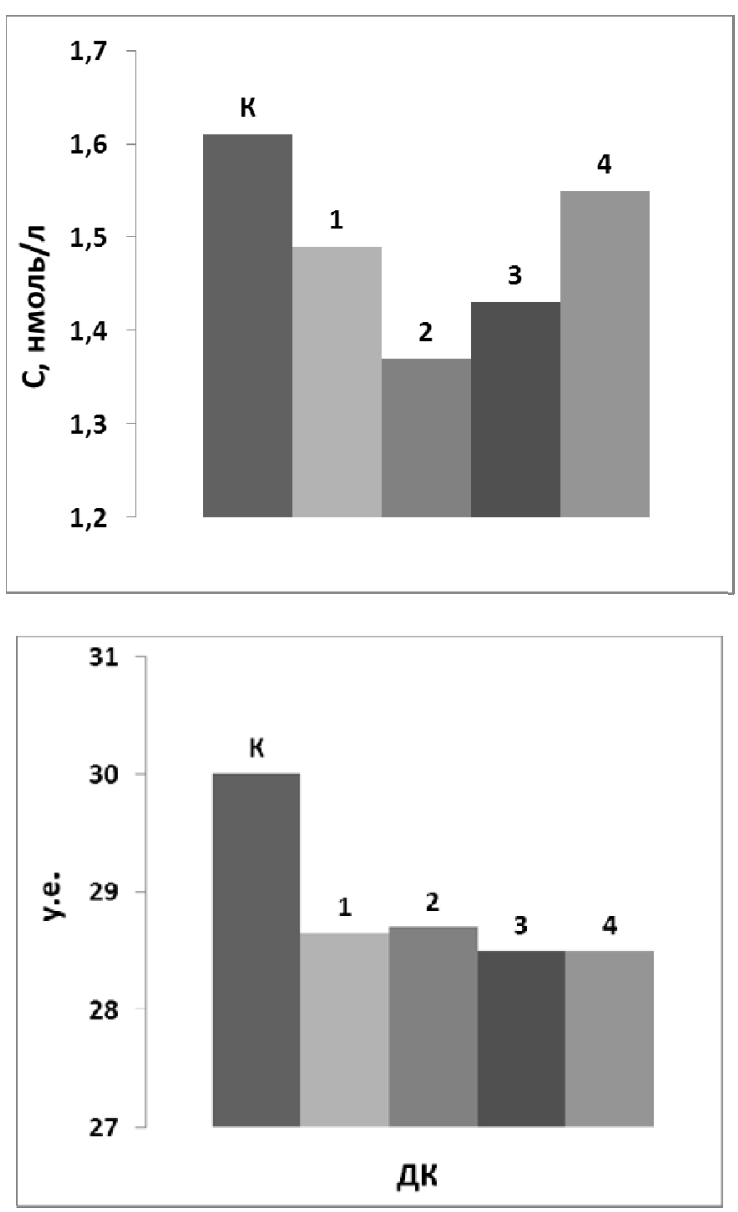

Рис. 2. Влияние ДКВ (1) и комплексных соединений цинка (2), меди (II) (3) и кальция (4) с ДКВ на содержание МДА в плазме крови (К - контроль, $\mathrm{p} \leq 0,05)$

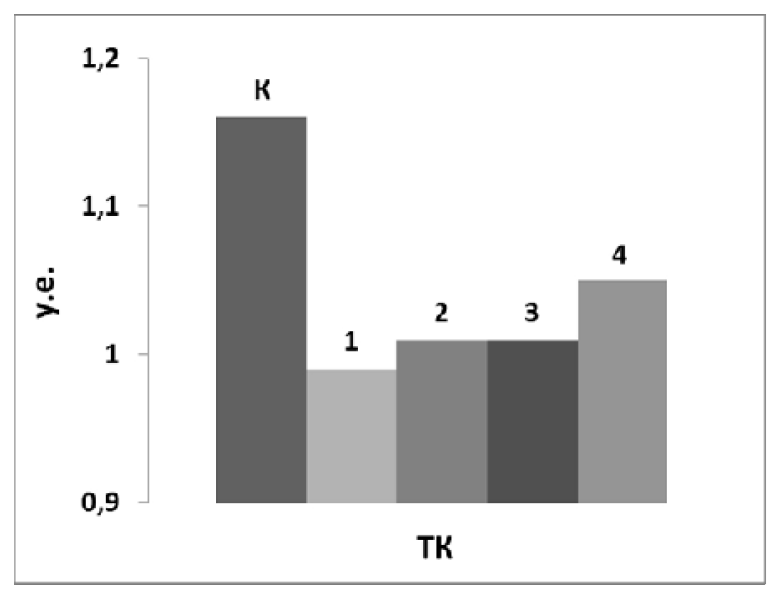

Рис. 3. Влияние ДКВ (1) и комплексных соединений цинка (2), меди (II) (3) и кальция (4) с ДКВ на содержание ДК и ТК в плазме крови (К - контроль, $\mathrm{p} \leq 0,05)$

Для оценки антиоксидантного статуса организма исследуют активность антирадикальных и антиперекисных ферментов в плазме крови. Одним из таких ферментов, широко распространенных в организме человека и животных и сохраняющих свою высокую активность длительное время, является каталаза. Роль каталазы в организме заключается в предотвращении накопления пероксида водорода, который образуется при дисмутации супероксидного аниона и при аэробном окислении восстановленных флавопротеидов. Спектрофотометрический метод определения активности каталазы является достаточно точным, чувствительным и простым в исполнении и поэтому широко используется для клинических и экспериментальных исследований [19].

Результаты проведенных экспериментов, представленные на рисунке 4, не выявили существенного влияния исследуемых соединений на активность каталазы.

Комплекс ДКВ с ионом цинка увеличивает активность каталазы на 1,5\% по сравнению с ДКВ. Комплексы, содержащие ионы меди (II) и кальция, увеличивают активность каталазы не более, чем раствор ДКВ.

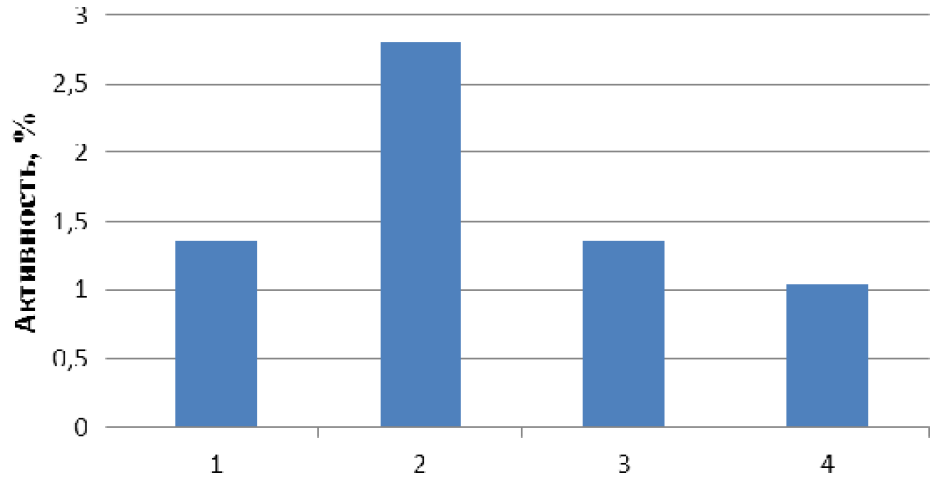

Рис. 4. Уровень активности каталазы в плазме крови для растворов ДКВ (1) и комплексных соединений цинка (2), меди (II) (3) и кальция (4) с ДКВ в концентрации растворов $0,005 \%$ 
Таким образом, комплексообразование дигидрокверцетина с ионами двухвалентных биогенных металлов приводит к повышению антиоксидантной активности флавоноида. Усиление антиоксидантного действия синтезированных комплексов может быть обусловлено сочетанием антиоксидантных свойств исходного флавоноида и ионов биогенных металлов.

Получение новых производных на основе природного антиоксиданта дигидрокверцетина, проявляющих усиленную биологическую активность, позволит расширить возможности создания новых лекарственных препаратов, обладающих антиоксидантными свойствами, используемых при лечении различных заболеваний. В свою очередь, это будет способствовать более полному использованию экстрактивных веществ древесины лиственницы для расширения ассортимента импортозамещающих лекарственных средств и повышению рентабельности химической переработки древесины лиственницы.

\section{Выводы}

Новые комплексные соединения, полученные на основе дигидрокверцетина, содержащие в своем составе ионы цинка, меди (II) и кальция, проявляют антиоксидантную активность, влияя на уровень ПОЛ в плазме крови. Комплексное соединение дигидрокверцетина с ионом цинка снижает содержание МДА, конечного продукта ПОЛ, в плазме крови на 14,9\% по сравнению с контролем, что превосходит в 2 раза этот показатель для ДКВ (7,5\%). Соответствующие показатели для КС ДКВ с ионами меди (II) и кальция составляют 11,2 и 3,7\%. Влияние комплексов на снижение по сравнению с контролем содержания в плазме крови первичных продуктов ПОЛ - ДК и ТК сопоставимо с соответствующими показателями для ДКВ. Комплексное соединение цинка с ДКВ увеличивает активность каталазы на 1,5\% по сравнению с ДКВ. Повышение активности каталазы под влиянием комплексов, содержащих ионы меди (II) и кальция, сравнимо по величине с действием ДКВ.

\section{Список литературы}

1. Червяковский Е.М., Курченко В.П., Костюк В.А. Роль флавоноидов в биологических реакциях с переносом электронов // Труды БГУ. 2009. Т. 4. Ч. 1. С. 9-26.

2. Патент №2158598 (РФ). Способ получения дигидрокверцетина / В.А. Бабкин, Л.А. Остроухова, Д.В. Бабкин, Ю.А. Малков / 2000.

3. Бабкин В.А., Остроухова Л.А., Трофимова Н.Н. Биомасса лиственницы: от химического состава до инновационных продуктов. Новосибирск: Изд-во СО РАН, 2011. 232 с.

4. De Souza R.F.V., De Giovani W.F. Synthesis, spectral and electrochemical properties of Al (III) and Zn (II) complexes with flavonoids // Spectrochimica Acta Part A. 2005. Pp. 1985-1990.

5. De Souza R.F., De Giovani W.F. Antioxidant properties of complexes of flavonoids with metal ions // Redox Rep. 2004. Vol. 9(2). Pp. 97-104.

6. Markovic J.M.D., Markovic Z.S., Brdaric T.P., Filipovic N.D. Comparative spectroscopic and mechanistic study of chelation properties of fisetin with iron in aqueous buffered solutions. Implications on in vitro antioxidant activity // Dalton Trans. 2011. N40. Pp. 4560-4571.

7. Pereira R.M.S., Andrades N.E.D., Paulino N., Sawaya A.C.H.F., Eberlin M.N., Marcucci M.C., Favero G.M., Novak E.M., Bydlowski S.P. Synthesis and Characterization of a Metal Complex Containing Naringin and $\mathrm{Cu}$, and its Antioxidant, Antimicrobial, Antiinflammatory and Tumor Cell Cytotoxicity // Molecules. 2007. N12. Pp. 1352-1366.

8. Panhwar Q.K., Memon Sh. Synthesis and evaluation of antioxidant and antibacterial properties of morin complexes // Journal of Coordination Chemistry. 2011. Vol. 64 (12). Pp. 2117-2129.

9. Panhwar Q.K., Memon Sh., Bhanger M.I. Synthesis, characterization, spectroscopic and antioxidation studies of $\mathrm{Cu}$ (II)-morin complex // Journal of Molecular Structure. 2010. Vol. 967. Pp. 47-53.

10. Symonowicz M., Kolanek M. Flavonoids and their properties to form chelate complexes // Biotechnol Food Sci. 2012. Vol. 76 (1). Pp. 35-41.

11. Tang H., Wang X., Yang S., Wang L. Synthesis, characterization and biological activities of Pt(II) and Pd(II) complexes with 2,3,4,5,7-pentahydroxyflavone // Rare Metals. 2004. Vol. 23. Pp. 38-42.

12. Panhwar Q.K., Memon Sh. Synthesis and properties of zirconium(IV) and molybdate(II) morin complexes // Journal of Coordination Chemistry. 2012. Vol. 65 (7). Pp. 1130-1143.

13. Panhwar Q.K., Memon Sh. Synthesis, Spectral Characterization and Antioxidant Activity of Tin(II)-Morin Complex // Pak. J. Anal. Environ. Chem. 2012. Vol. 13. N2. Pp. 159-168.

14. Костюк В.А., Потапович А.И. Биорадикалы и биоантиоксиданты. Минск, 2004. 174 с.

15. Trofimova N.N., Stolpovskaya E.V., Babkin V.A., Fedorov S.V., Kalabin G.A., Goryainov S.V., Zolotarev E.E., Safronov A.Yu., Kashevskii A.V., Zhitov R.G. The Structure and Electrochemical Properties of Metal Complexes with Dihydroquercetin // Russian Journal of Bioorganic Chemistry. 2015. Vol. 41. N7. Pp. 745-752.

16. Гончаренко М.С., Латинова А.М. Метод оценки перекисного окисления липидов // Лабораторное дело. 1985. №1. C. 60-61.

17. Арутюнян А.В., Дубинина Е.Е., Зыбина Н.Н. Методы оценки свободнорадикального окисления и антиоксидантной системы организма. Методические рекомендации. СПб, 2000. 104 с. 
18. Королюк М.А., Иванова Л.И., Майорова И.Г., Токарев В.Е. Метод определения активности каталазы // Лабораторное дело. 1988. №1. С. 16-19.

19. Патент №2553428 (РФ). Способ получения моно- и билигандных комплексных соединений ионов двухвалентных металлов - цинка, меди (II) и кальция, с дигидрокверцетином, обладающих усиленной антиоксидантной активностью / Н.Н. Трофимова, В.А. Бабкин, Е.В. Столповская. 2015.

20. Государственная фармакопея СССР: Вып. 2. Общие методы анализа. Лекарственное растительное сырье. М.: Медицина, 1989. $400 \mathrm{c}$.

Поступило в редакиию 7 июля 2016 г. После переработки 11 октября 2016 г.

Stolpovskaya E.V.*, Trofimova N.N., Babkin V.A. EVALUATION OF ANTIOXIDANT ACTIVITY OF COMPLEXES OF DIHYDROQUERCETIN WITH BIOGENIC METALS IONS

Federal Research Budget Institution, A.E. Favorsky Institute of Chemistry, Siberian Branch, Russian Academy

of Sciences, Favorsky St., 1, Irkutsk, 664033 (Russia), e-mail: stel@irioch.irk.ru

The antioxidant activity of complexes of dihydroquercetin (DHQ) with ions $\mathrm{Zn}^{2+}, \mathrm{Cu}^{2+}$ and $\mathrm{Ca}^{2+}$ have been investigated in experiments in vitro with blood plasma of healthy donors. The state of the lipid peroxidation (LPO) in blood plasma have been evaluated on the content of malondialdehyde (MDA), diene (DC) and triene (TC) conjugates. The impact of the complexes and DHQ on the enzyme catalase activity in blood plasma have been determined. It is found that complex of DHQ with zinc ion reduces the content of MDA in blood plasma of $14,9 \%$ compared with the control. This exceeds twice the significant for DHQ (7,5\%). The corresponding figures for complexes of DHQ with ions of copper (II) and calcium are amount to 11,2 and $3,7 \%$. Effect of complexes to decrease of DC and TC in blood plasma compared with control is comparable with the corresponding values for DHQ. Complex of DHQ with zinc ion increases catalase activity by $1,5 \%$ compared to DHQ. Complexes of DHQ with ions copper (II) and calcium increases catalase activity by no more than DHQ. catalase.

Keywords: dihydroquercetin, complex compounds, antioxidant activity, malondialdehyde, diene and triene conjugates,

\section{References}

1. Cherviakovskii E.M., Kurchenko V.P., Kostiuk V.A. Trudy BGU, 2009, vol. 4, no. 1, pp. 9-26. (in Russ.).

2. Patent 2158598 (RU). 2000. (in Russ.).

3. Babkin V.A., Ostroukhova L.A., Trofimova N.N. Biomassa listvennitsy: ot khimicheskogo sostava do innovatsionnykh produktov. [Biomass larch: from chemistry to innovative products]. Novosibirsk, 2011, 232 p. (in Russ.).

4. De Souza R.F.V., De Giovani W.F. Spectrochimica Acta Part A., 2005, pp. 1985-1990.

5. De Souza R.F., De Giovani W.F. Redox Rep., 2004, vol. 9(2), pp. 97-104.

6. Markovic J.M.D., Markovic Z.S., Brdaric T.P., Filipovic N.D. Dalton Trans, 2011, no. 40, pp. 4560-4571.

7. Pereira R.M.S., Andrades N.E.D., Paulino N., Sawaya A.C.H.F., Eberlin M.N., Marcucci M.C., Favero G.M., Novak E.M., Bydlowski S.P. Molecules, 2007, no. 12, pp. 1352-1366.

8. Panhwar Q.K., Memon Sh. Journal of Coordination Chemistry, 2011, vol. 64 (12), pp. 2117-2129.

9. Panhwar Q.K., Memon Sh., Bhanger M.I. Journal of Molecular Structure, 2010, vol. 967, pp. 47-53.

10. Symonowicz M., Kolanek M. Biotechnol Food Sci., 2012, vol. 76 (1), pp. 35-41.

11. Tang H., Wang X., Yang S., Wang L. Rare Metals, 2004, vol. 23, pp. 38-42.

12. Panhwar Q.K., Memon Sh. Journal of Coordination Chemistry, 2012, vol. 65 (7), pp. 1130-1143.

13. Panhwar Q.K., Memon Sh. Pak. J. Anal. Environ. Chem., 2012, vol. 13, no. 2, pp. 159-168.

14. Kostiuk V.A., Potapovich A.I. Bioradikaly i bioantioksidanty. [Bioradicals and bioantioxidants]. Minsk, 2004, 174 p. (in Russ.).

15. Trofimova N.N., Stolpovskaya E.V., Babkin V.A., Fedorov S.V., Kalabin G.A., Goryainov S.V., Zolotarev E.E., Safronov A.Yu., Kashevskii A.V., Zhitov R.G. Russian Journal of Bioorganic Chemistry, 2015, vol. 41, no. 7, pp. $745-752$.

16. Goncharenko M.S., Latinova A.M. Laboratornoe delo, 1985, no. 1, pp. 60-61. (in Russ.).

17. Arutiunian A.V., Dubinina E.E., Zybina N.N. Metody otsenki svobodnoradikal'nogo okisleniia $i$ antioksidantnoi sistemy organizma. Metodicheskie rekomendatsii. [Methods for evaluation of free radical oxidation and antioxidant system. Guidelines]. St. Petersburg, 2000, 104 p. (in Russ.).

18. Koroliuk M.A., Ivanova L.I., Maiorova I.G., Tokarev V.E. Laboratornoe delo, 1988, no. 1, pp. 16-19. (in Russ.).

19. Patent 2553428 (RU). 2015. (in Russ.).

20. Gosudarstvennaia farmakopeia SSSR: Vyp. 2. Obshchie metody analiza. Lekarstvennoe rastitel'noe syr'e. [State Pharmacopoeia of the USSR: Vol. 2. General methods of analysis. Medicinal plant material]. Moscow, 1989, 400 p. (in Russ.).

\footnotetext{
* Corresponding author.
} 